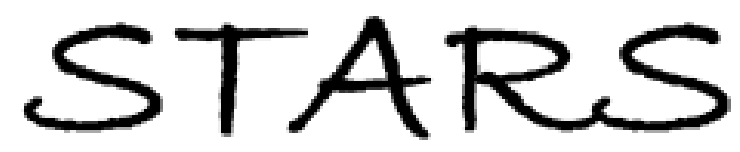

University of Central Florida

STARS

$1-1-2005$

\title{
On the relationship of magnetocrystalline anisotropy and stoichiometry in epitaxial L1(0) CoPt (001) and FePt (001) thin films
}

K. Barmak

J. Kim

L. H. Lewis

K. R. Coffey

University of Central Florida

M. F. Toney

Sipednsixtidagevforkesd ditti

University of Central Florida Libraries http://library.ucf.edu

This Article is brought to you for free and open access by the Faculty Bibliography at STARS. It has been accepted for inclusion in Faculty Bibliography 2000s by an authorized administrator of STARS. For more information, please contact STARS@ucf.edu.

\section{Recommended Citation}

Barmak, K.; Kim, J.; Lewis, L. H.; Coffey, K. R.; Toney, M. F.; Kellock, A. J.; and Thiele, J. -U., "On the relationship of magnetocrystalline anisotropy and stoichiometry in epitaxial L1(0) CoPt (001) and FePt (001) thin films" (2005). Faculty Bibliography 2000s. 4979.

https://stars.library.ucf.edu/facultybib2000/4979

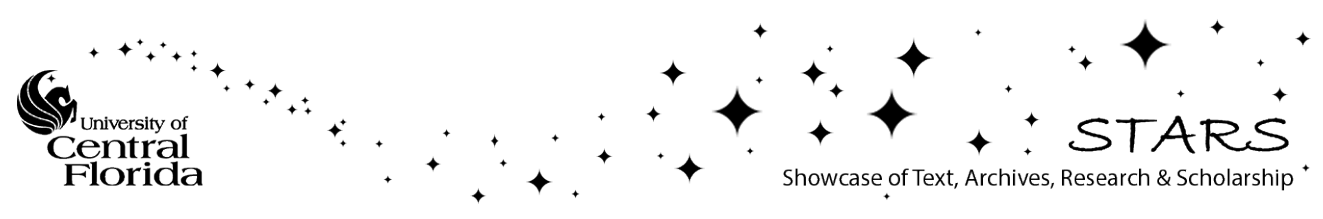




\section{Authors}

K. Barmak, J. Kim, L. H. Lewis, K. R. Coffey, M. F. Toney, A. J. Kellock, and J. -U. Thiele 


\section{On the relationship of magnetocrystalline anisotropy and stoichiometry in epitaxial $L 1_{0}$ CoPt (001) and FePt (001) thin films}

Cite as: J. Appl. Phys. 98, 033904 (2005); https://doi.org/10.1063/1.1991968

Submitted: 19 July 2004 . Accepted: 11 June 2005 . Published Online: 08 August 2005

K. Barmak, J. Kim, L. H. Lewis, K. R. Coffey, M. F. Toney, A. J. Kellock, and J.-U. Thiele

ARTICLES YOU MAY BE INTERESTED IN

Llo ordered phase formation in FePt, FePd, CoPt, and CoPd alloy thin films epitaxially grown on $\mathrm{MgO}(001)$ single-crystal substrates

Journal of Applied Physics 111, $07 A 708$ (2012); https://doi.org/10.1063/1.3672856

On the relationship of high coercivity and $\mathrm{L}_{0}$ ordered phase in CoPt and FePt thin films Journal of Applied Physics 86, 4527 (1999); https://doi.org/10.1063/1.371397

Direct formation of ordered CoPt and FePt compound thin films by sputtering Applied Physics Letters 66, 1692 (1995); https://doi.org/10.1063/1.113895

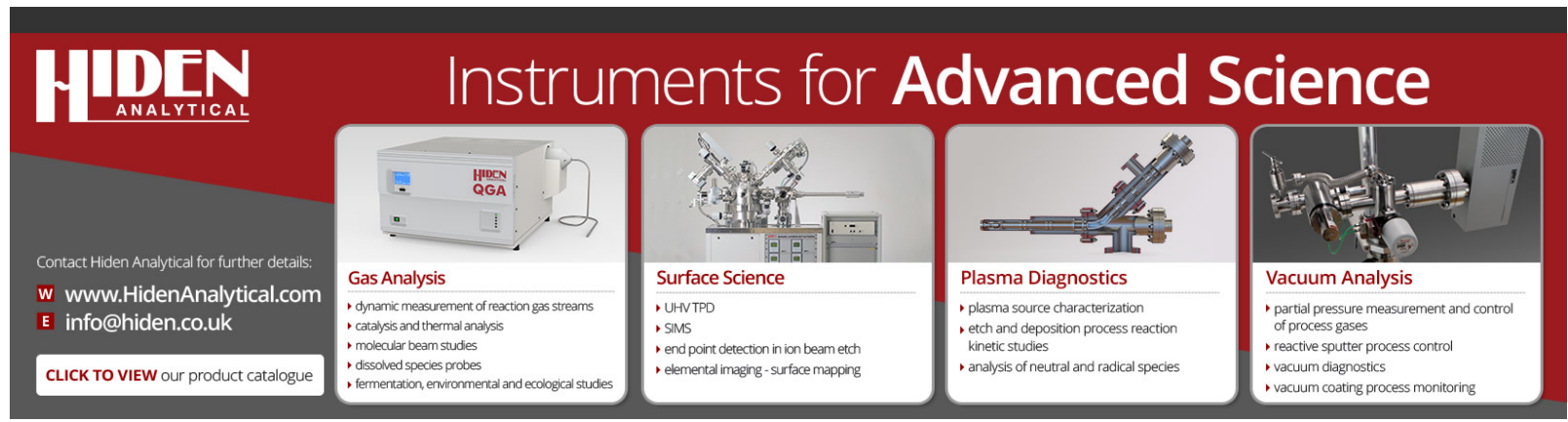




\title{
On the relationship of magnetocrystalline anisotropy and stoichiometry in epitaxial $L 1_{0}$ CoPt (001) and FePt (001) thin films
}

\author{
K. Barmak ${ }^{\text {a) }}$ \\ Data Storage Systems Center, Carnegie Mellon University, Pittsburgh, Pennsylvania 15213 \\ and Department of Materials Science and Engineering, Carnegie Mellon University, \\ Pittsburgh, Pennsylvania 15213 \\ J. Kim \\ Data Storage Systems Center, Carnegie Mellon University, Pittsburgh, Pennsylvania 15213 \\ L. H. Lewis \\ Materials Science Department, Brookhaven National Laboratory, Upton, New York 11973 \\ K. R. Coffey \\ University of Central Florida, Orlando, Florida 32816 \\ M. F. Toney \\ Stanford Linear Accelerator Center, Menlo Park, California 94025 \\ A. J. Kellock \\ International Business Machines Corporation (IBM), Almaden Research Center, \\ San Jose, California 95120 \\ J.-U. Thiele \\ Hitachi Global Storage Technologies, San Jose Research Center, San Jose, California 95120
}

(Received 19 July 2004; accepted 11 June 2005; published online 8 August 2005)

Two series of epitaxial CoPt and FePt films, with nominal thicknesses of 42 or $50 \mathrm{~nm}$, were prepared by sputtering onto single-crystal $\mathrm{MgO}(001)$ substrates in order to investigate the chemical ordering and the resultant magnetic properties as a function of alloy composition. In the first series, the film composition was kept constant, while the substrate temperature was increased from 144 to $704{ }^{\circ} \mathrm{C}$. In the second series the substrate temperature was kept constant at $704{ }^{\circ} \mathrm{C}$ for $\mathrm{CoPt}$ and $620^{\circ} \mathrm{C}$ for FePt, while the alloy stoichiometry was varied in the nominal range of 40-60-at. \% $\mathrm{Co}(\mathrm{Fe})$. Film compositions and thicknesses were measured via Rutherford backscattering spectrometry. The lattice and long-range order parameter for the $L 1_{0}$ phase were obtained for both sets of films using $\mathrm{x}$-ray diffraction. The room-temperature magnetocrystalline anisotropy constants were determined for a subset of the films using torque magnetometry. The order parameter was found to increase with increasing temperature, with ordering occurring more readily in $\mathrm{FePt}$ when compared with CoPt. A perpendicular anisotropy developed in CoPt for substrate temperatures above $534{ }^{\circ} \mathrm{C}$ and in $\mathrm{FePt}$ above $321^{\circ} \mathrm{C}$. The structure and width of the magnetic domains in CoPt and FePt, as seen by magnetic force microscopy, also demonstrated an increase in magnetic anisotropy with increasing temperature. For the films deposited at the highest temperatures $\left(704{ }^{\circ} \mathrm{C}\right.$ for $\mathrm{CoPt}$ and $620{ }^{\circ} \mathrm{C}$ for $\mathrm{FePt}$ ), the order parameter reached a maximum near the equiatomic composition, whereas the magnetocrystalline anisotropy increased as the concentration of Co or Fe was increased from below to slightly above the equiatomic composition. It is concluded that nonstoichiometric $L 1_{0} \mathrm{CoPt}$ and $\mathrm{FePt}$, with a slight excess of $\mathrm{Co}$ or $\mathrm{Fe}$, are preferable for applications requiring the highest anisotropies. (C) 2005 American Institute of Physics. [DOI: 10.1063/1.1991968]

\section{INTRODUCTION}

Alloy films of FePt and $\mathrm{CoPt}$ are attractive candidates for many advanced magnetic material applications such as ultrahigh-density magnetic recording media and magnetic actuators and drivers in micro- and nanoelectromechanical systems (MEMS/NEMS). ${ }^{1-72}$ The key feature underlying the exceptional magnetic properties of CoPt and FePt alloys is the chemically ordered $L 1_{0}$ phase, which, at the equiatomic composition, is comprised of alternating atomic planes of $\mathrm{Co}(\mathrm{Fe})$ and $\mathrm{Pt}$ along the unit-cell $c$ axis. The ordered phase

${ }^{a)}$ Electronic mail: katayun@andrew.cmu.edu in these two alloy systems manifests a large uniaxial magnetocrystalline anisotropy along the $c$ axis, with reported bulk values of $4.9 \times 10^{7} \mathrm{erg} / \mathrm{cm}^{3}$ for CoPt and $6.6 \times 10^{7} \mathrm{erg} / \mathrm{cm}^{3}$ for FePt. ${ }^{73-81}$ An even larger anisotropy constant on the order of $10^{8} \mathrm{erg} / \mathrm{cm}^{3}$ is reported for molecular-beam epitaxy (MBE)-grown $L 1_{0} \mathrm{FePt}$ films, consistent with the value provided by first-principles calculations. ${ }^{14,82}$

To date, a number of processing routes have been used to fabricate the $L 1_{0}$-ordered alloys of CoPt and FePt in monolithic thin-film form. These routes include, (i) the sputter deposition of alloys onto room-temperature substrates to form the chemically disordered face-centered-cubic (fcc, A1) 
TABLE I. Nominal compositions and thicknesses for the CoPt and FePt temperature series. The CoPt films had a 1-nm-thick Pt seed layer, whereas the FePt films had no seed layer. The table also lists the substrate temperature, $T_{s}$, the lattice parameters $a$ and $c$, the $c / a$ ratio, the full width at half maximum (FWHM) of the rocking curves for the (001), (002), and (003) reflections, the measured and maximum order parameters, $S$ and $S_{\max }$, respectively, and whether in-plane $c$-axis variants were present or not.

\begin{tabular}{|c|c|c|c|c|c|c|c|c|c|c|}
\hline Material & $\begin{array}{c}T_{s} \\
\left({ }^{\circ} \mathrm{C}\right)\end{array}$ & $a$ & $c$ & $c / a$ & $\begin{array}{c}\text { FWHM } \\
(001) \\
\left({ }^{\circ}\right)\end{array}$ & $\begin{array}{c}\text { FWHM } \\
(002) \\
\left({ }^{\circ}\right)\end{array}$ & $\begin{array}{c}\text { FWHM } \\
(003) \\
\left({ }^{\circ}\right)\end{array}$ & $S_{\max }$ & $S$ & $\begin{array}{c}\text { In- } \\
\text { plane } \\
\quad c \\
\text { variant }\end{array}$ \\
\hline \multirow[t]{7}{*}{$\mathrm{Co}_{52} \mathrm{Pt}_{48}(50 \mathrm{~nm}) / \mathrm{Pt}(1 \mathrm{~nm})$} & 276 & 3.770 & 3.766 & 0.999 & 2.317 & 1.096 & 0.207 & 0.96 & $0.03 \pm 0.03$ & No \\
\hline & 321 & 3.769 & 3.751 & 0.995 & 2.319 & 1.131 & 1.018 & 0.96 & $0.13 \pm 0.04$ & No \\
\hline & 368 & 3.765 & 3.744 & 0.994 & 1.945 & 1.148 & 1.257 & 0.96 & $0.19 \pm 0.04$ & No \\
\hline & 417 & 3.776 & 3.736 & 0.989 & 1.535 & 1.109 & 1.183 & 0.96 & $0.39 \pm 0.09$ & No \\
\hline & 534 & 3.788 & 3.724 & 0.983 & 1.193 & 0.957 & 0.974 & 0.96 & $0.61 \pm 0.15$ & No \\
\hline & 620 & 3.800 & 3.711 & 0.977 & 1.024 & 0.827 & 0.852 & 0.96 & $0.75 \pm 0.20$ & No \\
\hline & 704 & 3.802 & 3.698 & 0.973 & 0.692 & 0.589 & 0.603 & 0.96 & $0.88 \pm 0.03$ & Yes \\
\hline \multirow[t]{7}{*}{$\mathrm{Fe}_{52} \mathrm{Pt}_{48}(42 \mathrm{~nm}) /$ No seed } & 144 & 3.834 & 3.832 & 0.999 & $\cdots$ & 1.667 & $\cdots$ & 0.96 & $0.03 \pm 0.03$ & $\cdots$ \\
\hline & 180 & 3.826 & 3.822 & 0.999 & 3.404 & 1.518 & $\ldots$ & 0.96 & $0.04 \pm 0.04$ & $\cdots$ \\
\hline & 225 & 3.820 & 3.818 & 0.999 & $\cdots$ & 1.450 & 2.471 & 0.96 & $0.10 \pm 0.10$ & $\cdots$ \\
\hline & 321 & 3.839 & 3.787 & 0.986 & 2.036 & 1.492 & 1.504 & 0.96 & $0.39 \pm 0.01$ & No \\
\hline & 417 & 3.857 & 3.746 & 0.971 & 1.949 & 1.522 & 1.566 & 0.96 & $0.68 \pm 0.04$ & No \\
\hline & 534 & 3.874 & 3.714 & 0.959 & 1.233 & 1.107 & 1.112 & 0.96 & $0.82 \pm 0.08$ & No \\
\hline & 620 & 3.875 & 3.711 & 0.958 & 0.962 & 0.894 & 0.896 & 0.96 & $0.82 \pm 0.07$ & No \\
\hline
\end{tabular}

phase followed by postdeposition annealing to transform the A1 to the $L 1_{0}$-ordered phase, (ii) ion irradiation of disordered or partially ordered films, (iii) the annealing-induced reaction of epitaxially deposited elemental multilayers, and (iv) the direct formation of the $L 1_{0}$-ordered phase by molecularbeam epitaxy or sputter deposition onto single-crystal substrates at elevated temperatures. ${ }^{1-46,48-72}$

For the epitaxial $L 1_{0}$-ordered films of $\mathrm{CoPt}$ and $\mathrm{FePt}$, the magnetocrystalline anisotropy and the order parameter, i.e., the volume average fraction of atoms on the correct lattice sites, have been determined as a function of substrate temperature, substrate type and orientation, and seed layer type and thickness. However, since the ordering characteristics and the magnetocrystalline anisotropy for nonequiatomic compositions are different than those for the equiatomic composition, it is of interest to investigate the chemical ordering and the resultant magnetic properties as a function of alloy composition. In this work, we build on earlier work and report on $L 1_{0}$ ordering and anisotropy constant of epitaxial $\mathrm{CoPt}$ and $\mathrm{FePt}$ films with $\mathrm{Co}(\mathrm{Fe})$ concentrations in the range of 40-60 at. \%. ${ }^{6,7,9,11,13,14,20,21}$ As will be seen, the highest magnetic anisotropy does not correspond to the highest-order parameter, implying that nonstoichiometric $\mathrm{CoPt}$ and $\mathrm{FePt}$ films may be more suitable candidates for applications that require the highest anisotropy.

\section{EXPERIMENT}

CoPt and FePt alloy films, nominally 50 or $42 \mathrm{~nm}$ thick, were epitaxially grown by cosputtering from elemental targets. The substrates were polished $\mathrm{MgO}(001)$ single-crystal coupons of approximately $5 \times 5 \mathrm{~mm}^{2}$ for magnetic measurements and $10 \times 10 \mathrm{~mm}^{2}$ for $\mathrm{x}$-ray-diffraction studies. The coupons were cleaned with methanol prior to loading into the load-lock chamber. This chamber was pumped down into the $10^{-6}$-Torr range prior to substrate transfer into the sputtering chamber. The base pressure of the sputtering chamber was below $5 \times 10^{-8}$ Torr. The sputtering gas was $\mathrm{Ar}-4 \% \mathrm{H}_{2}$ at a pressure of 3 mTorr and a flow rate of 20 SCCM (standard cubic centimeter per minute). The choice of $\mathrm{Ar}-4 \% \mathrm{H}_{2}$ as the sputtering gas was made to inhibit film oxidation during deposition. The desired alloy film thicknesses and compositions were obtained with previously calibrated deposition rates determined for the individual elements by measuring the thicknesses of room-temperature-deposited pure $\mathrm{Co}, \mathrm{Fe}$, and Pt films for a series of deposition powers and times. Relatively low deposition rates of $0.1-0.2 \AA / \mathrm{s}$ were used for alloy film growth.

For each alloy system, two sets of films were prepared. For the first set, referred to as the "temperature series," the substrate temperature was varied at a fixed binary composition, whereas for the second set, the "composition series," the substrate temperature was fixed at 704 and $620^{\circ} \mathrm{C}$ for $\mathrm{CoPt}$ and $\mathrm{FePt}$, respectively, and the composition was varied as $\mathrm{Co}_{100-x} \mathrm{Pt}_{x}$ and $\mathrm{Fe}_{100-x} \mathrm{Pt}_{x}$ in the nominal range of $40<x$ $<60$ at. $\%$. The aim of fabricating the films in the temperature series was to identify a deposition temperature for which significant chemical ordering ( $S>0.8$, see below) would be obtained. These substrate temperatures, namely, 704 and $620^{\circ} \mathrm{C}$, were then used for the deposition of the CoPt and FePt composition series, respectively. The temperature series was also aimed at ensuring film order parameters and crystalline qualities comparable to those previously reported in the literature.

For all the CoPt films a 1-nm-thick Pt seed layer was used. For the FePt films no seed layer was used for the temperature series, whereas a bilayer seed of 1-nm Fe/1-nm Pt was used for the composition series. The choice of the latter was made on the basis of the previous report of Thiele et al. of the fabrication of high crystalline quality FePt films on $\mathrm{MgO}$ substrates using an $\mathrm{Fe} / \mathrm{Pt}$ bilayer seed. ${ }^{66}$ 
TABLE II. Measured composition, lattice parameters $a$ and $c, c / a$, full width at half maximum (FWHM) of the rocking curves for (001), (002) and (003) peaks, and order parameter, $S$, for $\mathrm{CoPt}(001)$ and $\mathrm{FePt}(001)$ films. $S_{\max }$ is the maximum order parameter for the given composition. The table also lists whether in-plane $c$-axis variants were present or not. The substrate temperature, $T_{s}$, for seed layer deposition was $620{ }^{\circ} \mathrm{C}$. The substrate temperature for deposition of the CoPt films was $704{ }^{\circ} \mathrm{C}$ and for deposition of the FePt films was $620^{\circ} \mathrm{C}$. See the discussion of film composition measurement errors.

\begin{tabular}{|c|c|c|c|c|c|c|c|c|c|c|}
\hline Material & $\begin{array}{c}\text { Composition } \\
x \\
\text { (at. \%) }\end{array}$ & $a$ & $c$ & $c / a$ & $\begin{array}{c}\text { FWHM } \\
(001) \\
\left({ }^{\circ}\right)\end{array}$ & $\begin{array}{c}\text { FWHM } \\
(002) \\
\left({ }^{\circ}\right)\end{array}$ & $\begin{array}{c}\text { FWHM } \\
(003) \\
\left({ }^{\circ}\right)\end{array}$ & $S_{\max }$ & $S$ & $\begin{array}{c}\text { In- } \\
\text { plane } \\
c \\
\text { variant }\end{array}$ \\
\hline \multirow[t]{6}{*}{$\mathrm{Co}_{x} \mathrm{Pt}_{100-x} / \mathrm{Pt}(1 \mathrm{~nm})$} & 37.5 & 3.810 & 3.812 & 1.001 & 0.783 & 0.564 & 0.596 & 0.75 & $0.20 \pm 0.01$ & Yes \\
\hline & 42.7 & 3.807 & 3.761 & 0.988 & 0.704 & 0.605 & 0.591 & 0.86 & $0.56 \pm 0.12$ & Yes \\
\hline & 46.4 & 3.801 & 3.723 & 0.979 & 0.709 & 0.617 & 0.618 & 0.93 & $0.80 \pm 0.20$ & Yes \\
\hline & 51.0 & 3.802 & 3.698 & 0.973 & 0.692 & 0.589 & 0.603 & 0.98 & $0.88 \pm 0.03$ & Yes \\
\hline & 53.4 & 3.791 & 3.690 & 0.973 & 0.784 & 0.640 & 0.658 & 0.93 & $0.88 \pm 0.06$ & Yes \\
\hline & 58.4 & 3.763 & 3.687 & 0.980 & 0.773 & 0.595 & 0.622 & 0.83 & $0.67 \pm 0.03$ & No \\
\hline \multirow[t]{4}{*}{$\mathrm{Fe}_{x} \mathrm{Pt}_{100-x} / \mathrm{Pt}(1 \mathrm{~nm}) / \mathrm{Fe}(1 \mathrm{~nm})$} & 46.2 & 3.870 & 3.721 & 0.961 & 1.237 & 1.161 & 1.146 & 0.92 & $0.89 \pm 0.02$ & No \\
\hline & 51.1 & 3.863 & 3.710 & 0.960 & 1.109 & 1.060 & 1.074 & 0.98 & $0.93 \pm 0.05$ & No \\
\hline & 52.0 & 3.857 & 3.706 & 0.961 & 1.151 & 1.087 & 1.098 & 0.96 & $0.89 \pm 0.06$ & No \\
\hline & 55.4 & 3.839 & 3.704 & 0.965 & 1.738 & 1.449 & 1.505 & 0.89 & $0.72 \pm 0.05$ & Yes \\
\hline
\end{tabular}

The substrate temperatures listed in Tables I and II are those for the center thermocouple from among five thermocouples embedded in a 3-in.-diameter silicon wafer that was separately used for temperature calibration in the absence of deposition. The temperature of the center thermocouple is listed here since the $\mathrm{MgO}$ coupons were placed in the center region of the substrate heater. The standard deviation of the center-to-edge temperature readings was as low as $2.7^{\circ} \mathrm{C}$ for a center temperature of $101^{\circ} \mathrm{C}$ and as high as $25.0^{\circ} \mathrm{C}$ for a center temperature of $620^{\circ} \mathrm{C}$. In addition, the variations in heating current during holds at temperature resulted in temperature variations of $\leqslant 15{ }^{\circ} \mathrm{C}$.

The $\mathrm{MgO}$ coupons were held at the specified temperature for 10-15 min prior to deposition. For the CoPt films of the composition series, the seed layer was deposited at $620^{\circ} \mathrm{C}$ and held for $1 \mathrm{~min}$, prior to heating or cooling to the desired temperature for alloy film deposition. For the FePt composition series, the bilayer seed and the alloy film were both deposited at $620^{\circ} \mathrm{C}$. For the FePt temperature series, given that no seed layer was used, the substrate was raised to and then held at the desired temperature for $10 \mathrm{~min}$ before the film deposition.

The composition of the second set of films, i.e., the CoPt and $\mathrm{FePt}$ composition series, was determined by Rutherford backscattering spectrometry, where the ratio of $\mathrm{Pt}$ and transition-metal atoms present in the deposited films can be determined with great accuracy (better than \pm 0.5 at. \%). To calculate the composition of the $L 1_{0}$ portion of the deposited films, it was assumed that the seed layer thicknesses were exact as given. The potential composition error introduced by this assumption is small and will be systematic, having an equal effect on all the samples in each experimental series. In other words, the presence of the seed layer does not affect conclusions based on comparisons of data within each series. To minimize the impact of channeling effects, the samples were rotated away from normal incidence. Film compositions are listed in Table II. As can be seen from the tables, the measured compositions and thicknesses were close to the intended, nominal values.
For the determination of the lattice and order parameters, the films were studied by both normal and in-plane $\mathrm{x}$-ray diffraction (XRD). This procedure allowed the lattice planes parallel and perpendicular to the film plane, respectively, to be probed. $\mathrm{Cu} K_{\alpha}$ radiation $(\lambda=1.541 \AA)$ and a graphite monochromator were used for all the diffraction scans. For the scans performed in the normal geometry (i.e., those probing the atomic planes parallel to the film plane) a Rigaku Geigerflex XRD system operating at $35 \mathrm{kV}$ and $25 \mathrm{~mA}$ was used. By contrast, for the in-plane scans and the rocking scans a Philips X'pert-MRD XRD system operating at $45 \mathrm{kV}$ and $35 \mathrm{~mA}$ was utilized. A beam incidence angle of $2^{\circ}$ with respect to the sample plane was adopted in the case of the in-plane scans.

For the determination of the unit-cell dimensions of the ordered structure, the in-plane lattice parameter, $a$, was determined using the (110) superlattice peak. The lattice parameter perpendicular to the film plane, $c$, was obtained by using the three (00l) peaks, namely, (001), (002), and (003), where available. For the disordered phase, the unit-cell dimension was obtained using the (200) peak. The lattice parameters are given in Tables I and II. The long-range order parameter $(S)$ was calculated as the average of the two order parameters determined from the ratios of superlattice-tofundamental $(001) /(002)$ and $(003) /(002)$ total integrated peak intensities. The long-range order parameter is given by $S=r_{\alpha}+r_{\beta}-1=\left(r_{\alpha}-x_{A}\right) / y_{\beta}=\left(r_{\beta}-x_{B}\right) / y_{\alpha}$, where $x_{A}$ and $x_{B}$ are the atom fractions of the two components, $y_{\alpha}$ and $y_{\beta}$ are the fraction of the lattice site types $\alpha$ and $\beta$ in the ordered structure, and $r_{\alpha}$ and $r_{\beta}$ are the fraction of each type of lattice site occupied by the correct types of atom ( $A$ on $\alpha$ and $B$ on $\beta$ ). $S$ as determined here represents the volume average longrange order parameter. ${ }^{68}$ The maximum order parameter for the given film composition is given by $S_{\max }=1-2 \Delta x$, where $\Delta x$ is the compositional deviation in atom fraction from the equiatomic composition 0.5 . Thus, for a 48 at. $\% \mathrm{Co}(\mathrm{Fe})$ or Pt alloy, $S_{\max }=1-(2 \times 0.02)=0.96$. 
TABLE III. Substrate temperature, saturation magnetization, coercivity from perpendicular hysteresis loops, magnetic anisotropies, and order parameters taken from Table II for $\mathrm{CoPt}(001)$ and $\mathrm{FePt}(001)$ films.

\begin{tabular}{|c|c|c|c|c|c|c|c|}
\hline Material & $\begin{array}{l}\text { Composition } \\
\text { (at. \% Co or Fe) }\end{array}$ & $\begin{array}{c}T_{s} \\
\left({ }^{\circ} \mathrm{C}\right)\end{array}$ & $\begin{array}{c}M_{s} \\
\left(\mathrm{emu} / \mathrm{cm}^{3}\right)\end{array}$ & $\begin{array}{l}H_{c} \\
(\mathrm{Oe})\end{array}$ & $\begin{array}{c}K_{\perp} \\
\left(\mathrm{erg} / \mathrm{cm}^{3}\right) \\
10^{7}\end{array}$ & $\begin{array}{c}K_{1} \\
\left(\mathrm{erg} / \mathrm{cm}^{3}\right) 10^{7}\end{array}$ & $S$ \\
\hline \multirow{4}{*}{$\mathrm{Co}_{x} \mathrm{Pt}_{100-x}$} & 46.4 & \multirow{3}{*}{704} & $807 \pm 68$ & 2235 & $1.6 \pm 0.2$ & $2.1 \pm 0.2$ & 0.80 \\
\hline & 51.0 & & $895 \pm 85$ & 1173 & $2.0 \pm 0.2$ & $2.6 \pm 0.2$ & 0.88 \\
\hline & 53.4 & & $895 \pm 76$ & 2074 & $2.5 \pm 0.2$ & $3.0 \pm 0.2$ & 0.88 \\
\hline & 51.9 & 620 & $911 \pm 83$ & 1352 & $2.4 \pm 0.2$ & $2.9 \pm 0.2$ & 0.75 \\
\hline \multirow{4}{*}{$\mathrm{Fe}_{x} \mathrm{Pt}_{100-x}$} & 46.2 & \multirow{4}{*}{620} & $1175 \pm 106$ & 969 & $2.6 \pm 0.2$ & $3.6 \pm 0.2$ & 0.89 \\
\hline & 51.1 & & $1070 \pm 83$ & 2105 & $4.1 \pm 0.3$ & $5.0 \pm 0.3$ & 0.93 \\
\hline & 52.0 & & $1176 \pm 101$ & 2263 & $4.5 \pm 0.4$ & $5.5 \pm 0.4$ & 0.89 \\
\hline & 55.4 & & $1197 \pm 114$ & 3683 & $\ldots$ & $\ldots$ & 0.72 \\
\hline
\end{tabular}

The ratios of the superlattice-to-fundamental peak intensities were calculated in a manner similar to that detailed by Cebollada et al. ${ }^{68}$ As an example, the (001) (002) ratio is given by

$$
\frac{I_{(001)}}{I_{(002)}}=\frac{F_{(001)}^{2}\left(L P e^{-2 M}\right)_{(001)}}{F_{(002)}^{2}\left(L P e^{-2 M}\right)_{(002)}},
$$

where $I$ is the total integrated intensity of the given peak. This intensity was approximated by using the absorptioncorrected, integrated intensity obtained during the $\theta-2 \theta$ scan multiplied by the rocking-scan full width at half maximum (FWHM) of the peak (Tables I and II). For the absorption correction to the integrated intensities, the correction factor is given by $[1-\exp (-2 \mu t) / \sin \theta]$, where $\mu$ is the weighted average linear absorption coefficient, $t$ is the film thickness, either nominal or measured where available, and $\theta$ is the Bragg angle of the given reflection. The absorption coefficients were calculated using the measured lattice constants and again either the nominal or, where available, the measured film composition. $F$ in Eq. (1) is the structure factor and is given by

$F=4\left(x_{A} f_{A}+x_{B} f_{B}\right)$

for the fundamental peaks, here (002), and

$F=2 S\left(f_{A}-f_{B}\right)$

for the superlattice peaks, here (001), or (003),

where $x_{A}$ and $x_{B}$ are mole fractions of the chemical species $A$ (Co or $\mathrm{Fe}$ ) and $B(\mathrm{Pt})$, respectively, and $f_{A}$ and $f_{B}$ are the atomic form factors for the given species and reflection. ${ }^{83}$

In Eq. (1), $L$ is the Lorentz factor and, for epitaxial films, it is given as $L=1 /(\cos \theta \sin \theta){ }^{68} P$ is the polarization factor and for our diffraction geometry, $P=(1$ $\left.+\cos ^{2} 2 \theta \cos ^{2} 2 \theta_{m}\right) /\left(1+\cos ^{2} 2 \theta_{m}\right)$, where $\theta_{m}=26.57^{\circ}$ is the Bragg angle for the graphite monochromator. ${ }^{84}$ The DebyeWaller factor $M$ contained in the exponent of Eq. (1) was calculated from the root-mean-square displacement amplitude $\sigma$ as $2 M=(Q \sigma)^{2}$, where $Q=(4 \pi / \lambda) \sin \theta$ is the scattering vector for the wavelength $\lambda$ and Bragg angle $\theta$. As noted by Cebollada et al., both static and dynamic (i.e., vibrational) displacements contribute to $\sigma$ and, therefore, to $M{ }^{68}$ The static displacements are the crystallographic disorder that is frozen or fixed, and for thin films they are found to be large and even dominant, with typical values of $0.1-0.2 \AA .^{21,85} \mathrm{~A}$ value of $\sigma=0.14$ was used in this work. The calculated order parameters are listed in Tables I and II. The error in the order parameter $S$ was calculated as the standard deviation of the two values for $(001) /(002)$ and $(003) /(002)$, and it was found to be typically below 0.1 .

Tables I and II also list whether in-plane $c$ variants are present or not. These variants are ordered regions with their $c$ axes, i.e., the [001] unit-cell axes of the ordered phase, in the plane of the film rather than perpendicular to the plane of the film as would be desired, and they give rise to a (200)/(020) peak in the normal XRD scans.

Magnetic characterization was carried out both parallel and perpendicular to the film plane using a vibrating-sample magnetometer (VSM) at room temperature in the applied field ranges of -18.5 to $+18.5 \mathrm{kOe}$. No corrections for demagnetization were made. The room-temperature anisotropies of the thin-film samples were determined with a torque magnetometer operated in the applied field range of 0 to $-18.5 \mathrm{kOe}$. In detail, the intrinsic anisotropy constant is defined as

$$
K_{1}=K_{1}^{\mathrm{eff}}+2 \pi M_{s}^{2}
$$

where $K_{1}^{\text {eff }}$ is the perpendicular anisotropy energy $\left(K_{\perp}\right)$ that is measured using the " $45^{\circ}$ method" and high-field extrapolation. $^{21,86}$ The errors in the values of $K_{1}$ arise from the extrapolations needed to extract the values of $K_{1}^{\mathrm{eff}}$ and $M_{s}$ in the Myajima and Sato $45^{\circ}$ method and vary for individual fits as shown in Figs. 4(a) and 4(b). The errors are dominated by errors in $K_{1}^{\text {eff }}{ }^{86}$ The values of $K_{1}, K_{1}^{\text {eff }}$, and $M_{s}$ are given in Table III.

Magnetic force microscopy (MFM) was used to investigate the magnetic microstructure of samples in the thermally demagnetized state. A Nanoscope III atomic force microscope was used in the tapping Mode at a lift height of $25 \mathrm{~nm}$ to capture the films' magnetic domain character. No special sample preparation was applied to the films' surfaces. The relatively magnetically "hard" CoCr-coated Si tip was magnetized vertically along the tip axis, thereby allowing the perpendicular component of the stray field emanating from the sample surface to be detected and imaged as strongly contrasting black-and-white magnetic domains that may be 

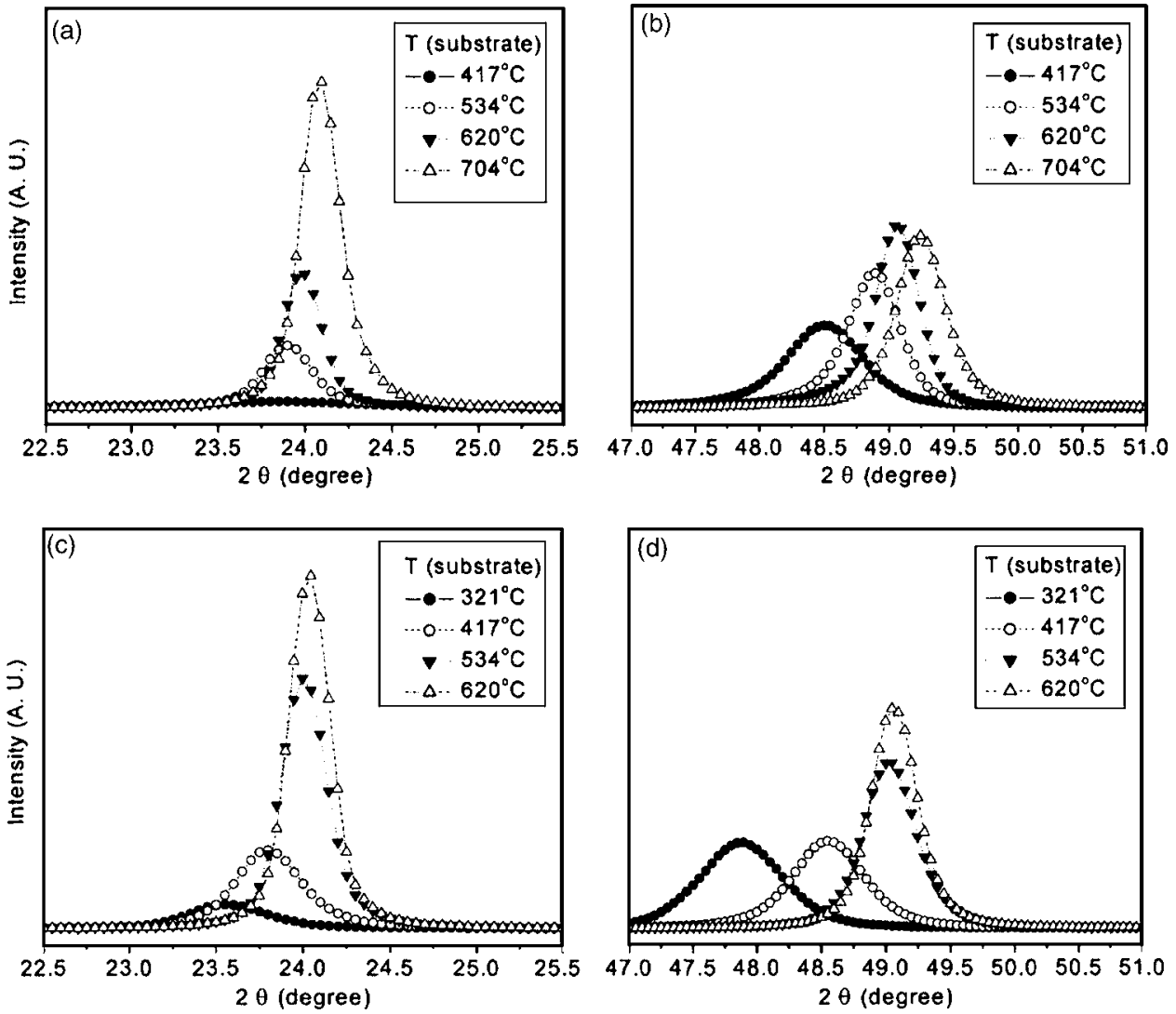

FIG. 1. $\theta-2 \theta$ XRD scans of $\mathrm{CoPt}(001)$ and FePt(001) epitaxial films obtained as a function of substrate temperature, [(a) and (b)] (001) superlattice and (002) fundamental peaks of $\mathrm{CoPt}$, and [(c) and (d)] (001) superlattice and (002) fundamental peaks of $\mathrm{FePt}$, respectively. interpreted as domains with magnetization oriented parallel and antiparallel to the surface normal. The film topographic images recorded with atomic force microscopy (AFM) proved to be featureless and are not reported on here.

\section{RESULTS AND DISCUSSION}

As can be seen in Table I and Figs. 1(a)-1(d) and 2, the order parameter, $S$, and the extent of tetragonality (reflected in the $c / a$ ratio) of the $L 1_{0}$ unit cell for both CoPt and FePt increase with increasing substrate temperature. The qualitative evidence of ordering and the associated changes in the crystal structure (cubic to tetragonal) and the interplanar spacings are seen as shifts in the fundamental and superlattice peaks in Figs. 1(a)-1(d). Table I further shows that the FWHM of the rocking curves for both types of films decreases with increasing substrate temperature, indicating an improvement in the epitaxial quality of the films with increasing temperature. The trends, as well as the absolute values, of the order parameter, the degree of tetragonality, and the epitaxial quality of the films are in good agreement with the results of previous studies of CoPt and FePt thin films deposited by sputtering and molecular-beam epitaxy in the temperature range of $25-700{ }^{\circ} \mathrm{C} .{ }^{6,7,9,11,13,14,20,21}$ The lattice parameters and the $c / a$ ratios obtained at the highest substrate temperatures for CoPt and FePt also compare reasonably well with those for bulk samples, namely, $a$ $=3.803 \AA, c=3.701 \AA$, and $c / a=0.973$ for $\mathrm{CoPt}$ and $a$ $=3.853 \AA, c=3.713 \AA$, and $c / a=0.964$ for FePt $^{87}$

Table I and Fig. 2(a) indicate a greater tendency for ordering in FePt as compared with $\mathrm{CoPt}$, as evidenced by, for example, the higher value of the order-parameter $S$ at a given
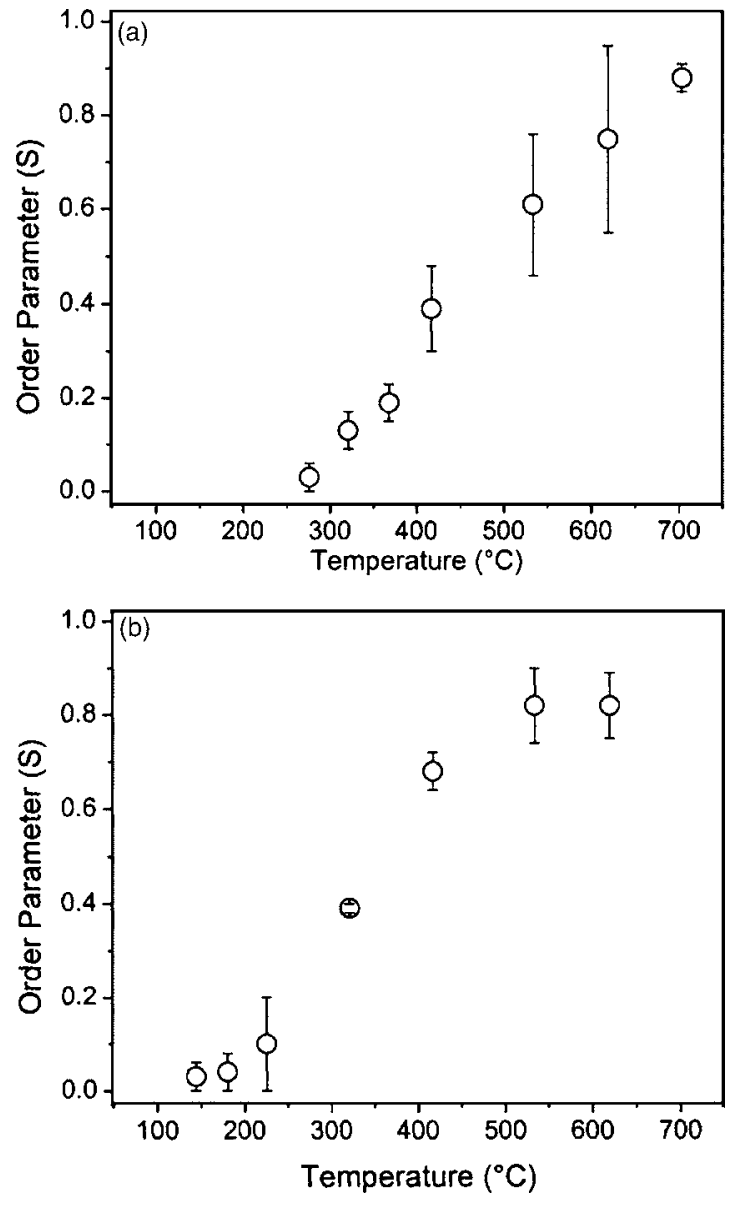

FIG. 2. The order parameter $(S)$ for (a) $\operatorname{CoPt}(001)$ and (b) $\operatorname{FePt}(001)$ epitaxial films as a function of substrate temperature. 

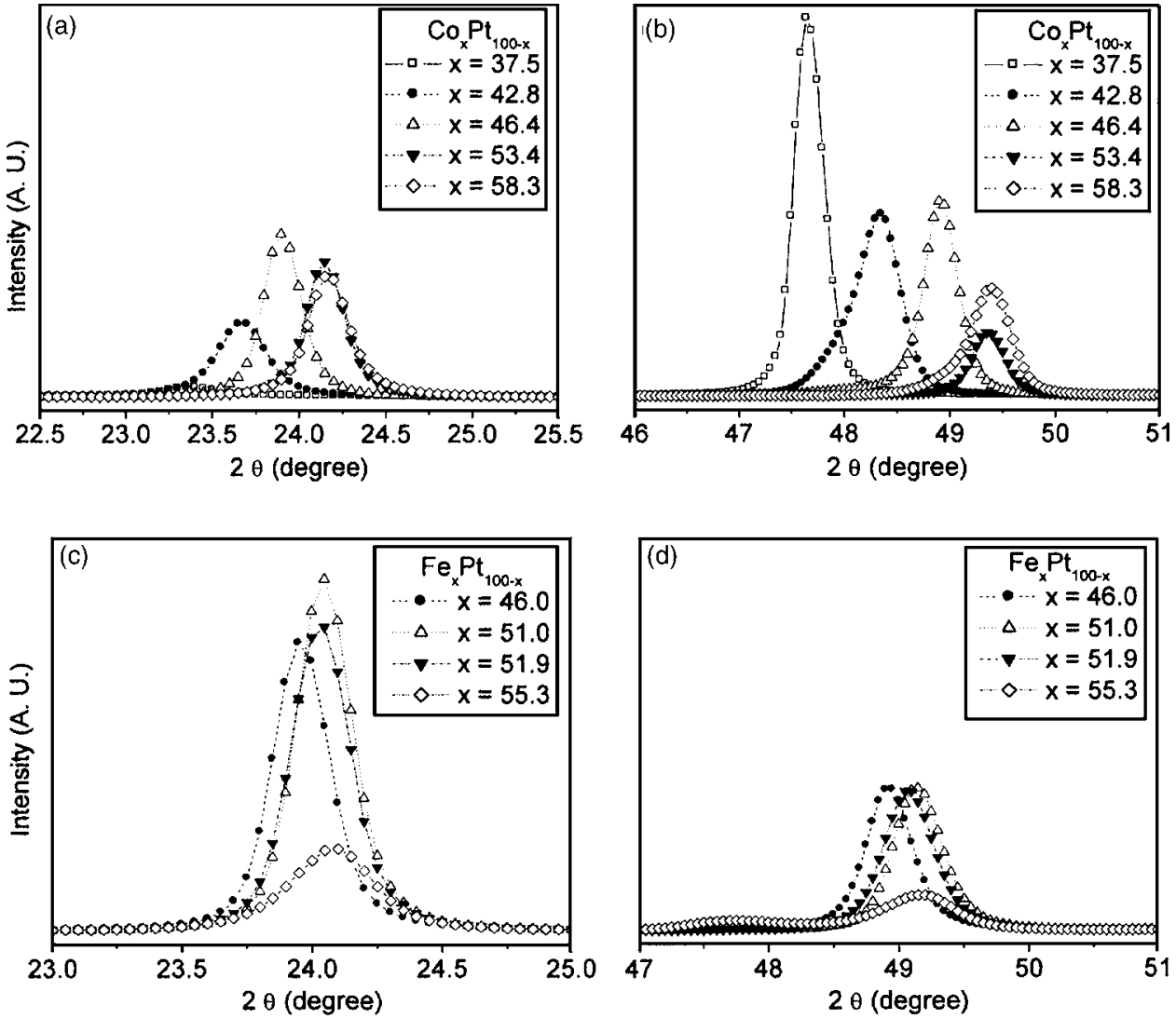

FIG. 3. $\theta-2 \theta$ XRD scans of $\mathrm{CoPt}(001)$ and $\mathrm{FePt}(001)$ epitaxial films as a function of film composition. [(a) and (b)] (001) superlattice and (002) fundamental peaks of $\mathrm{CoPt}$, and [(c) and (d)] (001) superlattice and (002) fundamental peaks of FePt, respectively. The CoPt and FePt films were deposited at substrate temperatures of 704 and $620^{\circ} \mathrm{C}$, respectively. substrate temperature. As an illustration, at the deposition temperature of $417^{\circ} \mathrm{C}, S$ is found to be 0.39 and 0.68 for $\mathrm{CoPt}$ and FePt, respectively. The greater ease of ordering in FePt compared with CoPt is in agreement with other studies of epitaxial and polycrystalline thin films, ${ }^{11,28,65}$ and it is believed to be a reflection of the higher equilibrium orderdisorder temperature $\left(1300\right.$ vs $\left.825^{\circ} \mathrm{C}\right)$, and, thus, the larger magnitude of the driving force for ordering in FePt compared with CoPt. ${ }^{88}$ However, at higher substrate temperatures, the order parameter for FePt reaches a plateau, as seen in Table I and Fig. 2.

The evolution of peak location and relative intensity of the superlattice and fundamental peaks is shown in Figs. 3(a)-3(d), and the order parameter of the films as a function of CoPt and FePt stoichiometry is plotted in Figs. 4(a) and 4(b). Table II and Figs. 4(a) and 4(b) show that the maximum order parameters of 0.88 for $\mathrm{CoPt}$ and 0.93 for $\mathrm{FePt}$ are obtained at the composition closest to the equiatomic composition, namely, 51 at. $\% \mathrm{Co}(\mathrm{Fe})$, as might have been expected for the $L 1_{0}$-ordered structure. However, for $\mathrm{CoPt}$, the high value of the order parameter persists up to a composition of 53.4 at. \% Co. Interestingly, the best epitaxial quality, as quantified by the FWHM of the rocking curves, is also seen for the films with compositions of 51 at. $\% \mathrm{Co}(\mathrm{Fe})$ (Table II).

The evolution of the magnetic properties resulting from the $L 1_{0}$ chemical ordering of the CoPt and the FePt epitaxial films can best be followed by an examination of the $M-H$ curves for the CoPt and FePt films in Figs. 5(a)-5(d) and Figs. 6(a)-6(d). The temperature series magnetic data of Figs. 5(a)-5(d) show that the major hysteresis curves acquire squareness, remanence and coercivity in the direction perpendicular to the film as the deposition temperature is increased, for a given constant composition. Symmetrically, both film compositions exhibit a reduction in those parameters in the in-plane direction with increased substrate deposition temperature. The perpendicular $M-H$ curves obtained from both film types shown in the figure exhibit an initially sharp reversal, indicative of a nucleation barrier for the formation of the oppositely magnetized domains. For samples prepared at lower temperatures, the nucleation of the negatively (or oppositely) magnetized domain occurs before the external positive field is reduced to zero, because of the demagnetization field of the sample in the perpendicular direction. For films deposited at higher temperatures, a higher nucleation barrier is present and the nucleation is delayed until the external field has reached zero and become negative, and is now aiding the sample's demagnetization field. Note that an increased sample thickness, in films with a uniformly high degree of chemical order, has also been observed to promote nucleation in external positive fields. ${ }^{21}$ The perpendicular $M-H$ curves of the $\mathrm{Fe}_{52} \mathrm{Pt}_{48}$ film deposited at temperatures greater than $321{ }^{\circ} \mathrm{C}$ show little difference from one another. Taken together, these results indicate that perpendicular anisotropy develops in the $\mathrm{Co}_{52} \mathrm{Pt}_{48}$ sample for $T_{s}>534{ }^{\circ} \mathrm{C}$ and in the $\mathrm{Fe}_{52} \mathrm{Pt}_{48}$ sample for $T_{s}>321{ }^{\circ} \mathrm{C}$, with these temperatures reflecting the greater ease of ordering and the formation of [001]-oriented $L 1_{0}$ phase in FePt as compared to CoPt.

The composition series magnetic data of Figs. 6(a)-6(d) show the development of perpendicular magnetic anisotropy in the $\mathrm{FePt}$ and $\mathrm{CoPt}$ films. Analogous to observations of the 

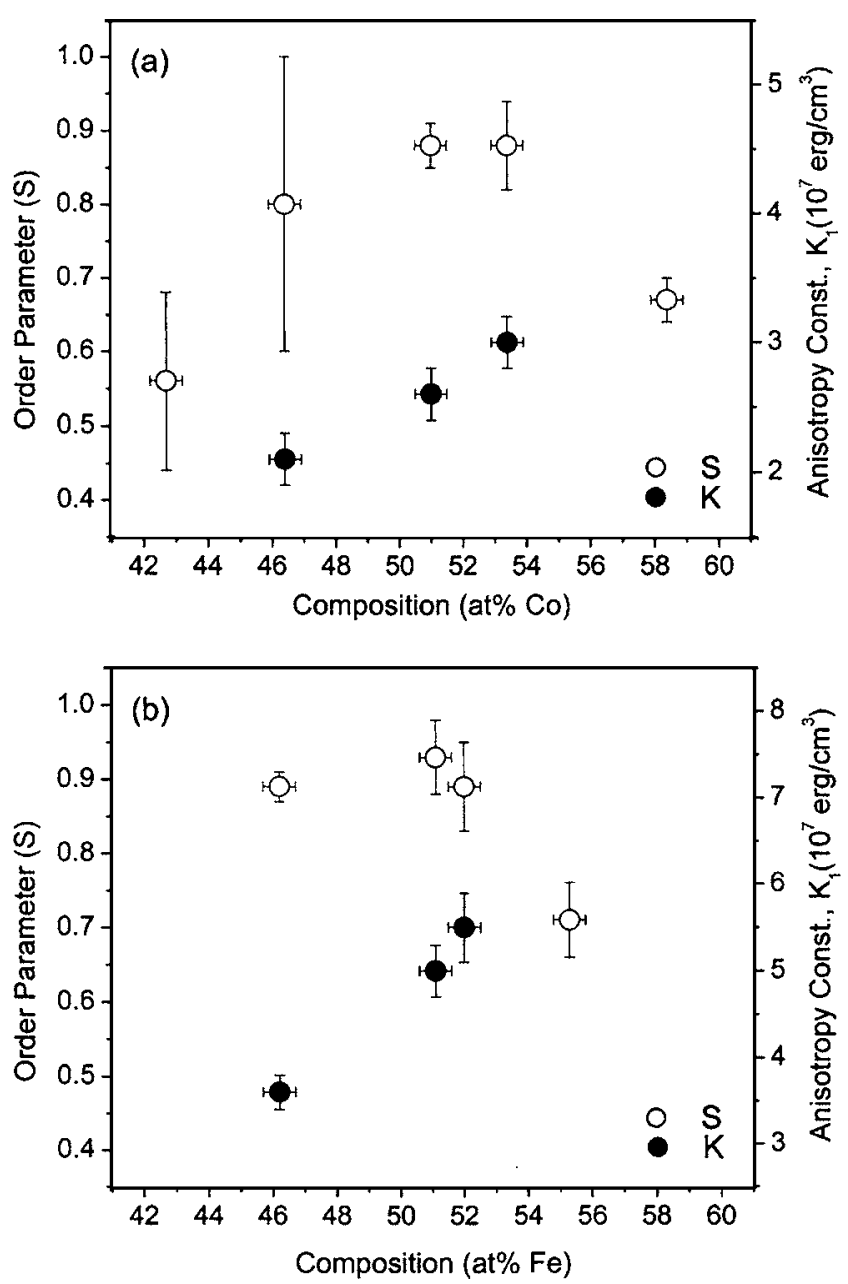

FIG. 4. The order parameter $(S)$ and magnetocrystalline anisotropy constant $\left(K_{l}\right)$ as a function of film composition for (a) CoPt and (b) FePt. The CoPt and FePt films were deposited at substrate temperatures of 704 and $620^{\circ} \mathrm{C}$, respectively.

temperature series of films, a progression in the squareness, remanence, and coercivity in the direction perpendicular to the films is found as a function of composition. As seen in the temperature series, nucleation barriers affect the initial reversal in the perpendicular direction for almost all samples. The saturation magnetization values, $M_{s}$, in Table III for the $\mathrm{CoPt}$ and FePt films studied here can be compared with those reported for bulk $\mathrm{CoPt}$ and $\mathrm{FePt}$, namely, 800 and $1140 \mathrm{emu} / \mathrm{cm}^{3}$, respectively. ${ }^{81}$ Further, the $M_{s}$ values for the $\mathrm{CoPt}$ films are within the range measured for polycrystalline thin films. ${ }^{89}$

The structure and width of the magnetic domains as revealed by MFM are representative of the thermally demagnetized state of the temperature series films assessed perpendicular to the film plane. The MFM images presented in Fig. 7 are similar to those obtained by Belliard et al. ${ }^{90}$ and Thiele et $a l .{ }^{21}$ However, while in the previous studies the influence of film thickness on the magnetic domains in fully ordered films of varying thickness was investigated, here the anisotropy constant of the film is varied at constant film thickness. Guidance towards interpretation of the MFM domain images may be taken from calculation of a uniform distribution of magnetic domains with anisotropy axes oriented perpendicu- lar to the surface of a planar ferromagnetic body, as outlined in Ref. 91 Although it is true that films of this study, with thicknesses on the order of $50 \mathrm{~nm}$, do not match the model criterion of an infinitely large ferromagnetic plate, they are nevertheless approximately ten times the thickness of the $L 1_{0}$ phase domain-wall width and therefore the model may be applied with caution to elucidate the development of anisotropy with annealing condition in these films. It is calculated that the magnetostatic energy decreases as the width of the domain decreases; at the same time the number of domain walls, and hence the total domain wall energy, increases. Minimization of the total energy balance yields an approximate expression for the magnetic domain width $d$, with $d$ $\propto \sqrt{\gamma \cdot l} / M_{s}$. In the previous expression, $\gamma$ is the surface energy of the domain wall and therefore is an expression of the magnetocrystalline anisotropy, $l$ is the thickness of the plate and $M_{S}$ is the saturation magnetization. Therefore under conditions of constant film thickness $l$ and constant saturation magnetization $M_{S}$, increases in the imaged domain width may be directly correlated with increases in the magnetic anisotropy within each sample series. The MFM micrographs of the $\mathrm{Fe}_{52} \mathrm{Pt}_{48}$ temperature series, Figs. 7(e)-7(h), show that an increase in the deposition substrate temperature from 321 to $620^{\circ} \mathrm{C}$ is accompanied by an increase in the domain width and thus in the anisotropy, consistent with the simple model above. This trend is also apparent for the data of the $\mathrm{CoPt}$ samples shown in Figs. 7(c) and 7(d), however, for the CoPt films deposited at lower temperature this trend does not apply. This is believed to be due to the presence of significant in-plane anisotropy as evidenced by the rather long, regular, and well-connected stripe-type domains [Fig. 7(a)]. Images taken from CoPt films deposited at the higher temperatures show less continuity or interconnectedness of domains, signaling the loss of an in-plane magnetization component. The features in Fig. 7 may be attributed to a stronger perpendicular magnetic anisotropy in the FePt films as compared to the CoPt films, and an increase in anisotropy with deposition temperature, in agreement with the structural studies and the $M-H$ curve studies.

The computed magnetocrystalline anisotropy constants $K_{1}$ were obtained as function of film composition according to Eq. (2) for a subset of the CoPt and FePt films. These values are listed in Table III and plotted in Figs. 4(a) and 4(b). The anisotropy constant was not determined for the 55.3 at. $\% \mathrm{Fe}$ film, because a large coercivity was measured in the plane of the film, indicating that in-plane $c$-axis variants were present (Fig. 6, Table II). The computed anisotropy constants for CoPt and FePt are somewhat smaller than those reported by other researchers for similar films. ${ }^{11,21}$ No simple correlation between the film anisotropy constant and the order parameter is found. For CoPt and FePt the order parameter decreases on either side of the equiatomic composition, whereas the anisotropy increases as the $\mathrm{Co}(\mathrm{Fe})$ content increases from below to slightly above the equiatomic composition. Thus, the highest anisotropies are found for compositions that are slightly $\mathrm{Co}$ or $\mathrm{Fe}$ rich. 

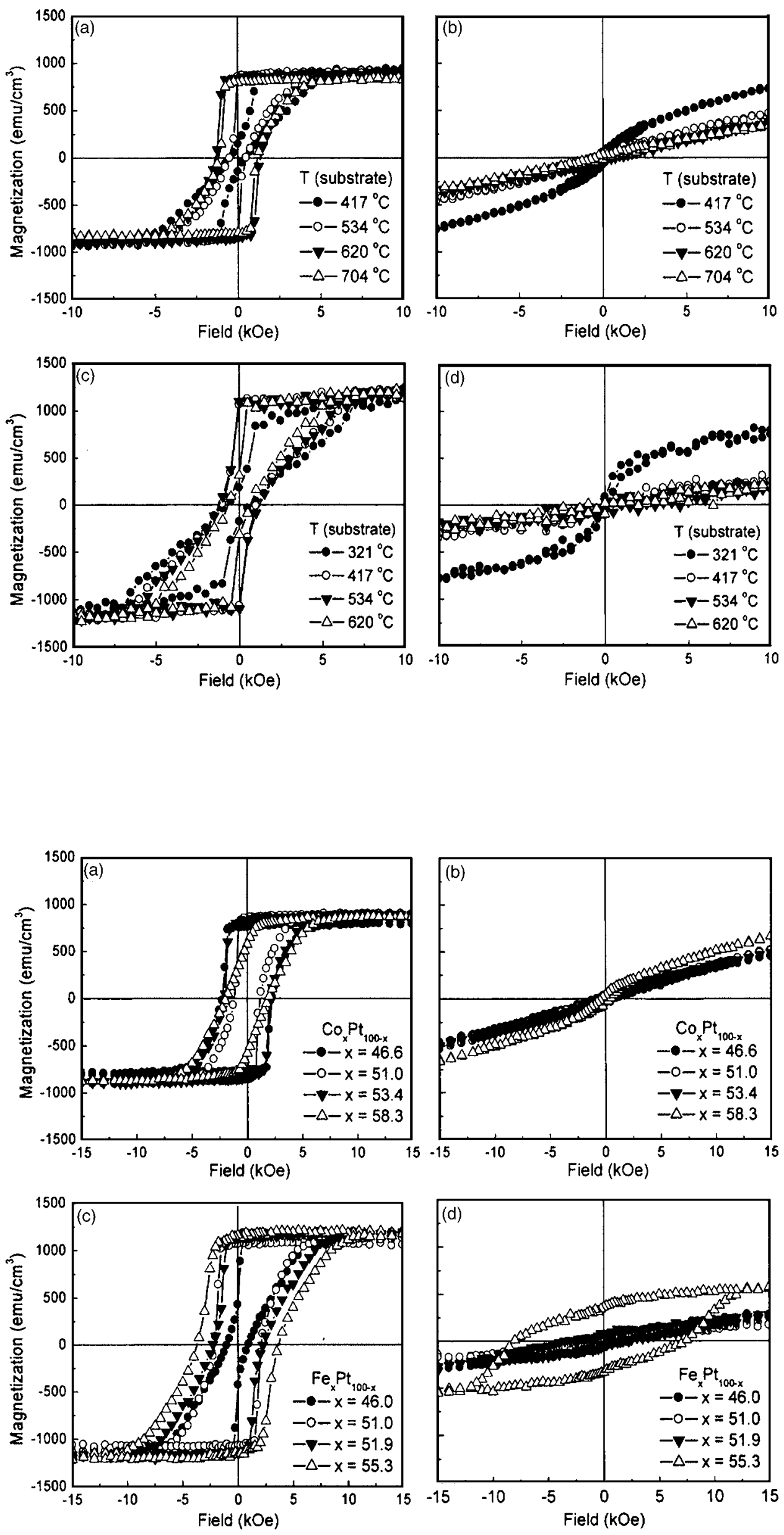

FIG. 5. $(M-H)$ hysteresis loops for $\mathrm{Co}_{52} \mathrm{Pt}_{48}(001)$ and $\mathrm{Fe}_{52} \mathrm{Pt}_{48}(001)$ epitaxial films as a function of substrate temperature. Perpendicular and parallel loops for $\mathrm{CoPt}[(\mathrm{a})$ and (b)] and FePt $[(\mathrm{c})$ and (d)], respectively.
FIG. 6. $(M-H)$ hysteresis loops as a function of film composition for substrate deposition temperatures of $704{ }^{\circ} \mathrm{C}$ for $\mathrm{CoPt}[(\mathrm{a})$ and (b)] and $620{ }^{\circ} \mathrm{C}$ for FePt $[(\mathrm{c})$ and $(\mathrm{d})]$, respectively. The perpendicular loops are given in (a) and (c), and the parallel loops in (b) and (d). 

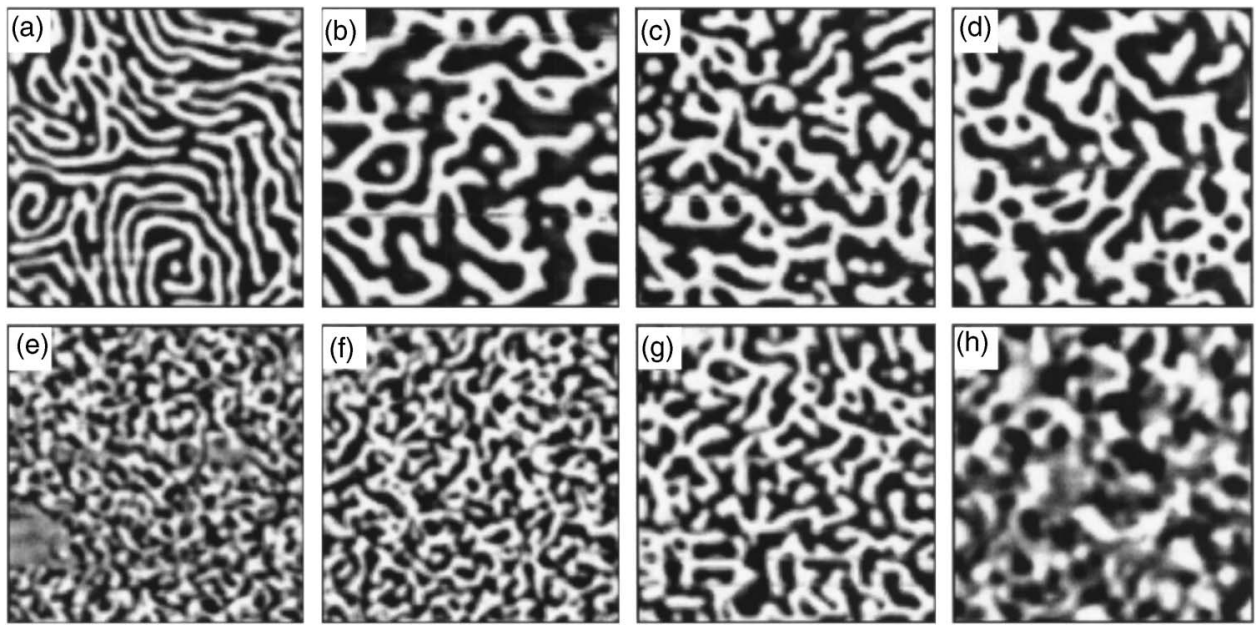

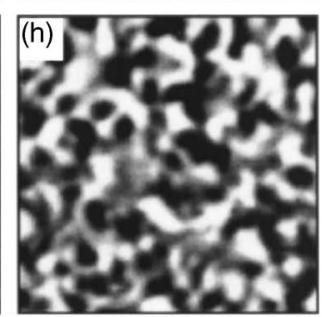

FIG. 7. MFM micrographs (3 $\left.\times 3 \mu \mathrm{m}^{2}\right)$ of $\mathrm{Co}_{52} \mathrm{Pt}_{48}$ (001) [(a)-(d)] and $\mathrm{Fe}_{52} \mathrm{Pt}_{48}$ (001) [(e)-(h)] epitaxial films as a function of substrate temperature. These temperatures are for $\mathrm{Co}_{52} \mathrm{Pt}_{48}$ (a) 417, (b) 534, (c) 620, and (d) $704{ }^{\circ} \mathrm{C}$, and for $\mathrm{Fe}_{52} \mathrm{Pt}_{48}$ (e) 321 , (f) $417,(g) 534$, and (h) $620^{\circ} \mathrm{C}$.

\section{CONCLUSIONS}

X-ray-diffraction and magnetization studies show FePt to order more readily than $\mathrm{CoPt}$, in agreement with other studies. For both alloy systems, the order parameter and the extent of unit-cell tetragonality increase with increasing substrate temperature. The epitaxial quality of the films is also seen to improve with temperature. With regard to alloy stoichiometry, the order parameter shows a maximum near the equiatomic composition in both $\mathrm{CoPt}$ and $\mathrm{FePt}$, as is expected for the $L 1_{0}$ structure.

Magnetization studies reveal the presence of nucleation barriers for magnetic reversal of the films in the perpendicular direction that are consistent with the development of perpendicular anisotropy observed at higher substrate temperatures. The structure and width of the magnetic domains as revealed by magnetic force microscopy also evidence an increase in magnetic anisotropy with increasing deposition temperature. This anisotropy evolution is quantified by determination of the intrinsic anisotropy constant $K_{1}$ for a subset of the studied films. While the order-parameter $S$ for both alloys systems is maximized in the vicinity of the equiatomic composition, the anisotropy constant increases as the $\mathrm{Co}(\mathrm{Fe})$ content is increased from below to slightly above the compositions. It is believed that a slight excess of $\mathrm{Co}(\mathrm{Fe})$ increases the magnetization of the alloy, resulting in an increase in the magnetocrystalline anisotropy constant without significantly reducing the chemical order parameter. The polarization of Pt may also play a role. The results of these experiments indicate that $\mathrm{CoPt}$ and $\mathrm{FePt}$ alloys with a slight excess of $\mathrm{Co}$ or $\mathrm{Fe}$ may be preferable for applications that require high anisotropy.

\section{ACKNOWLEDGMENTS}

Research was performed in part at BNL under the auspices of the U.S. D.O.E., Division of Materials Sciences, Office of Basic Energy Sciences under Contract No. DEAC02-98CH10886. Two of the authors (K.B.) and (J.K.) acknowledge funding support from the NSF under Contract Nos. DMR-9411146 and ECD-8907068. Portions of this research were carried out at the Stanford Synchrotron Radiation Laboratory, a national user facility operated by Stanford
University on behalf of the U.S. Department of Energy, Office of Basic Energy Sciences.

${ }^{1}$ V. Georgescu and V. Tutovan, Thin Solid Films 75, L15 (1981).

${ }^{2}$ V. Tutovan and V. Georgescu, Thin Solid Films 83, 253 (1983).

${ }^{3}$ J. A. Aboaf, S. R. Herd, and E. Klokholm, IEEE Trans. Magn. 19, 1514 (1983).

${ }^{4}$ K. Inomata, T. Sawa, and S. Hashimoto, J. Appl. Phys. 64, 2537 (1988).

${ }^{5}$ B. M. Lairson, and B. M. Clemens, Appl. Phys. Lett. 63, 1438 (1993).

${ }^{6}$ B. M. Lairson, M. R. Visokay, S. M. Brennan, R. Sinclair, and B. M. Clemens, Mater. Res. Soc. Symp. Proc. 311, 9 (1993).

${ }^{7}$ B. M. Lairson, M. R. Visokay, E. E. Marinero, R. Sinclair, and B. M. Clemens, J. Appl. Phys. 74, 1922 (1993).

${ }^{8}$ A. Tsoukatos, H. Wan, G. C. Hadjipanayis, Y. Zhang, and M. Waite, J. Magn. Magn. Mater. 118, 387 (1993).

${ }^{9}$ A. Cebollada, D. Weller, J. Sticht, G. R. Harp, R. F. C. Farrow, R. F. Marks, R. Savoy, and J. C. Scott, Phys. Rev. B 50, 3419 (1994).

${ }^{10}$ K. R. Coffey, M. A. Parker, and K. J. Howard, IEEE Trans. Magn. 31, 2737 (1995).

${ }^{11}$ M. R. Visokay and R. Sinclair, Appl. Phys. Lett. 66, 1692 (1995).

${ }^{12}$ K. Takahashi, S. Mittani, M. Sano, H. Fujimori, H. Nakajima, and M. Osawa, Appl. Phys. Lett. 67, 1016 (1995).

${ }^{13}$ R. F. C. Farrow, D. Weller, R. F. Marks, M. F. Toney, S. Hom, G. R. Harp, and A. Cebollada, Appl. Phys. Lett. 69, 1166 (1996).

${ }^{14}$ R. F. C. Farrow, D. Weller, R. F. Marks, M. F. Toney, A. Cebollada, and G. R. Harp, J. Appl. Phys. 79, 5967 (1996).

${ }^{15}$ K. Barmak, R. A. Ristau, K. R. Coffey, M. A. Parker, and J. K. Howard, J. Appl. Phys. 79, 5330 (1996).

${ }^{16}$ R. Ristau, K. Barmak, D. Hess, K. R. Coffey, M. A. Parker, and J. K. Howard, Mater. Res. Soc. Symp. Proc. 398, 557 (1996).

${ }^{17}$ S. H. Liou, Y. Liu, S. S. Malhotra, M. Yu, and D. J. Sellmyer, J. Appl. Phys. 79, 5060 (1996)

${ }^{18}$ R. A. Ristau, K. Barmak, K. R. Coffey, and J. K. Howard, Mater. Res. Soc. Symp. Proc. 475, 119 (1997).

${ }^{19}$ J. P. Liu, C. P. Luo, Y. Liu, and D. J. Sellmyer, Appl. Phys. Lett. 72, 483 (1998).

${ }^{20}$ R. F. C. Farrow, D. Weller, R. F. Marks, M. F. Toney, D. J. Smith, and M. R. McCartney, J. Appl. Phys. 84, 934 (1998).

${ }^{21}$ J.-U. Thiele, L. Folks, M. F. Toney, and D. K. Weller, J. Appl. Phys. 84, 5686 (1998).

${ }^{22}$ R. A. Ristau, F. Hofer, K. Barmak, K. R. Coffey, and J. K. Howard, Micron 29, 33 (1998).

${ }^{23}$ R. A. Ristau, K. Barmak, L. H. Lewis, K. R. Coffey, and J. K. Howard, Mater. Res. Soc. Symp. Proc. 577, 347 (1999).

${ }^{24}$ S. Jeong, M. E. McHenry, and D. E. Laughlin, Mater. Res. Soc. Symp. Proc. 577, 365 (1999).

${ }^{25}$ M. Futamoto, N. Inaba, Y. Hirayama, K. Ito, and Y. Honda, J. Magn. Magn. Mater. 193, 36 (1999).

${ }^{26}$ T. Suzuki, K. Harada, N. Honda, and K. Ouchi, J. Magn. Magn. Mater. 193, 85 (1999).

${ }^{27}$ N. Sharma, S. M. Casey, G. A. Jones, and P. J. Grundy, J. Magn. Magn. Mater. 193, 93 (1999).

${ }^{28}$ R. A. Ristau, K. Barmak, L. Henderson-Lewis, K. R. Coffey, and J. K. 
Howard, J. Appl. Phys. 86, 4527 (1999).

${ }^{29}$ R. A. Ristau, K. Barmak, K. R. Coffey, and J. K. Howard, J. Mater. Res 14, 3263 (1999).

${ }^{30}$ K. Barmak, J. M. Rickman, C. Michaelsen, R. A. Ristau, J. Kim, G. A. Lucadamo, D. T. Carpenter, and W. S. Tong, J. Vac. Sci. Technol. A A17, 1950 (1999).

${ }^{31}$ N. Li and B. M. Lairson, IEEE Trans. Magn. 35, 1077 (1999).

${ }^{32}$ C. Chen, O. Kitakami, S. Okamoto, and Y. Shimada, Appl. Phys. Lett. 76, 3218 (2000).

${ }^{33}$ D. K. Weller, et al., IEEE Trans. Magn. 36, 10 (2000)

${ }^{34}$ S. Sun, C. B. Murray, D. K. Weller, L. Folks, and A. Moser, Science 287, 1989 (2000).

${ }^{35}$ T. Suzuki, T. Kiya, N. Honda, and K. Ouchi, IEEE Trans. Magn. 36, 2417 (2000).

${ }^{36}$ J. A. Christodoulides, Y. Huang, Y. Zhang, G. C. Hadjipanayis, I. Panagiotopoulos, and D. Niarchos, J. Appl. Phys. 87, 6938 (2000).

${ }^{37}$ C. P. Luo, S. H. Liou, and D. J. Sellmyer, J. Appl. Phys. 87, 6941 (2000).

${ }^{38}$ A. Kikitsu, A. Murayama, K. Hyomi, and C. M. Falco, J. Appl. Phys. 87, 6944 (2000).

${ }^{39}$ C. Chen, O. Kitakami, S. Okamoto, and Y. Shimada, J. Appl. Phys. 87, 6947 (2000).

${ }^{40}$ S.-Y. Bae, K.-Ho Shin, J.-Y. Jeong, and J.-G. Kim, J. Appl. Phys. 87, 6953 (2000).

${ }^{41}$ M. M. Schwickert, K. A. Hannibal, M. F. Toney, M. Best, J.-U. Thiele, A. J. Kellock, and D. Weller, J. Appl. Phys. 87, 6956 (2000).

${ }^{42}$ M. Yu, Y. Liu, and D. J. Sellmyer, J. Appl. Phys. 87, 6959 (2000).

${ }^{43}$ B. Bian and D. E. Laughlin, J. Appl. Phys. 87, 6962 (2000).

${ }^{44}$ S. Jeong, Y-N. Hsu, M. E. McHenry, and D. E. Laughlin, J. Appl. Phys. 87, 6950 (2000).

${ }^{45}$ S. Jeong, Y-N. Hsu, M. E. McHenry, and D. E. Laughlin, IEEE Trans. Magn. 36, 2945 (2000).

${ }^{46}$ Y-N. Hsu, S. Jeong, D. N. Lambeth, and D. E. Laughlin, IEEE Trans. Magn. 36, 2945 (2000).

${ }^{47}$ S. Sun, E. E. Fullerton, D. Weller, and C. B. Murray, IEEE Trans. Magn. 37, 1239 (2001)

${ }^{48}$ Y. Endo, N. Kikuchi, O. Kitakami, and Y. Shimada, J. Appl. Phys. 89, 7065 (2001).

${ }^{49}$ J. P. Attané, Y. Samson, A. Marty, D. Halley, and C. Beigné, Appl. Phys. Lett. 79, 794 (2001).

${ }^{50}$ O. Kitakami, Y. Shimida, K. Oikawa, H. Daimon, and K. Fukamichi, Appl. Phys. Lett. 78, 1104 (2001).

${ }^{51}$ T. Suzuki and K. Ouchi, IEEE Trans. Magn. 37, 1283 (2001).

${ }^{52}$ S. Jeong, M. E. McHenry, and D. E. Laughlin, IEEE Trans. Magn. 37, 1309 (2001).

${ }^{53}$ Y. N. Hsu, S. Jeong, D. E. Laughlin, and D. N. Lambeth, J. Appl. Phys. 89, 7068 (2001).

${ }^{54}$ O. Kitakami, Y. Shimida, K. Oikawa, H. Daimon, and K. Fukamichi, Appl. Phys. Lett. 79, 2001 (2001).

${ }^{55}$ S. Jeong, A. G. Roy, D. E. Laughlin, and M. E. McHenry, J. Appl. Phys. 91, 8813 (2002).

${ }^{56}$ Y. Xu, J. S. Chen, D. Dai, and J. P. Wang, IEEE Trans. Magn. 38, 2042 (2002).

${ }^{57}$ T. Shima, T. Moriguchi, S. Mitani, K. Takanashi, H. Ito, and S. Ishio, IEEE Trans. Magn. 38, 2791 (2002).

${ }^{58}$ D. Ravelosona, et al., IEEE Trans. Magn. 37, 1643 (2001).

${ }^{59}$ T. Suzuki, H. Kanazawa, and A. Sakuma, IEEE Trans. Magn. 38, 2794 (2002).

${ }^{60}$ T. Maeda, A. Kikitsu, T. Kai, T. Nagase, H. Aikawa, and J. Akiyama, IEEE Trans. Magn. 38, 2796 (2002).

${ }^{61}$ T. Maeda, T. Kai, A. Kikitsu, T. Nagase, and J.-I. Akiyama, Appl. Phys. Lett. 80, 2147 (2002).
${ }^{62}$ S. Jeong, T. Ohkubo, A. G. Roy, D. E. Laughlin, and M. E. McHenry, J. Appl. Phys. 91, 6863 (2002).

${ }^{63}$ K. Barmak, J. Kim, R. A. Ristau, and L. H. Lewis, IEEE Trans. Magn. 38, 2799 (2002).

${ }^{64}$ J. Zhou, R. Skomski, L. Xingzhong, T. Wei, G. C. Hadjipanayis, and D. J. Sellmyer, IEEE Trans. Magn. 38, 2802 (2002).

${ }^{65}$ K. Barmak, J. Kim, S. Shell, E. B. Svedberg, and J. K. Howard, Appl. Phys. Lett. 80, 4268 (2002).

${ }^{66}$ J.-U. Thiele, K. R. Coffey, M. F. Toney, J. A. Hedstrom, and A. J. Kellock, J. Appl. Phys. 91, 6595 (2002).

${ }^{67}$ S. Kang, J. W. Harrell, and D. E. Nikles, Nano Lett. 2, 1033 (2002).

${ }^{68}$ A. Cebollada, R. F. C. Farrow, and M. F. Toney, Magnetic Nanostructures, edited by H. S. Nalwa, (American Scientific Publisher, California, 2002), pp. 93-122.

${ }^{69}$ R. Skomski, A. Kashyap, and D. J. Sellmyer, IEEE Trans. Magn. 39, 2917 (2003).

${ }^{70}$ M. F. Toney, W. Y. Lee, J. A. Hedstrom, and A. Kellock, J. Appl. Phys. 93, 9902 (2003).

${ }^{71}$ K. Barmak, J. Kim, L. H. Lewis, K. R. Coffey, M. F. Toney, A. J. Kellock, and J.-U. Thiele, J. Appl. Phys. 95, 7501 (2004).

${ }^{72} \mathrm{O}$. Cugat, in Proceedings of the 17th International Workshop on Rare Earth Magnets and Their Applications, edited by G. C. Hadjipanayis and M. J. Bonder, (Rinton Press, Princeton, NJ, 2002) pp. 478-489.

${ }^{73}$ A. S. Darling, Platinum Met. Rev. 7, 96 (1963).

${ }^{74}$ R. A. McCurrie and P. Gaunt, Philos. Mag. 13, 567 (1966).

${ }^{75}$ P. Gaunt, Philos. Mag. 13, 579 (1966).

${ }^{76}$ P. Brissonneau, A. Blanchard, and M. Schlenker, J. Laugier, J. Appl. Phys. 39, 1266 (1968)

${ }^{77}$ L. M. Magat, G. V. Ivanova, L. V. Solina, N. N. Schegoleva, and Y. S. Shur, Fiz. Met. Metalloved.. 29, 400 (1970).

${ }^{78}$ D. J. Craik, Platinum Met. Rev. 16, 129-137 (1972).

${ }^{79}$ O. A. Ivanov, L. V. Solina, V. A. Demshina, and L. M. Magat, Phys. Met. Metallogr. 35, 81 (1973).

${ }^{80}$ A. Y. Yermakov and V. V. Maykov, Fiz. Met. Metalloved. 60, 113 (1985).

${ }^{81}$ T. Klemmer, D. Hoydick, H. Okumura, B. Zhang, and W. A. Soffa, Scr. Metall. Mater. 33, 1793 (1995), and references therein.

${ }^{82}$ G. H. O. Daalderop, P. J. Kelly, and M. F. H. Schuurmans, Phys. Rev. B 44, 12054 (1991).

${ }^{83}$ International Tables for Crystallography, edited by A. J. C. Wilson, (The International Union of Crystallography, Boston, MA, 1992), Vol. C, p. 479, p. 484

${ }^{84}$ B. E. Warren, X-ray Diffraction, (Addison-Wesley, Reading, PA 1969), p. 208.

${ }^{85}$ M. F. Toney, J. N. Howard, J. Richer, G. L. Borges, J. G. Gordon, O. R. Melroy, D. Yee, and L. B. Sorensen, Phys. Rev. Lett. 75, 4472 (1995).

${ }^{86}$ H. Miyajima and K. Sato, J. Appl. Phys. 47, 4669 (1976).

${ }^{87}$ W. B. Pearson, Lattice Spacings and Structures of Metals and Alloys, (Pergammon, New York, 1967); P. Vilars and L. D. Culvert, Pearson's Handbook of Crystallographic Data for Intermetallic Phases (ASM International, Materials Park, OH, 1991); JCPDS-International Center for Diffraction Data, CoPt, Card No. 43-1358 and FePt, Card No. 43-1359 (1997).

${ }^{88}$ Binary Alloy Phase Diagrams, edited by T. B. Massalski, H. Okamoto, P. R. Subramanian, and L. Kacprzak, (ASM International, Materials Park, OH, 1990), p. 1225-1752.

${ }^{89}$ J. Kim, Ph.D. thesis, Lehigh University, Bethelehm, Pennsylvania (2001). ${ }^{90}$ L. Belliard, J. Miltat, V. Kottler, V. Mathet, C. Chappert, and T. Valet, J. Appl. Phys. 81, 5315 (1997).

${ }^{91}$ S. Chikazumi and Stanley H. Charap, Physics of Magnetism, (Robert E. Krieger Publishing Company, Malabar, FL, 1984), p. 226. 